\title{
Effects of Kaempferol, an Antioxidant, on the Bioavailability and Pharmacokinetics of Nimodipine in Rats
}

\author{
Ji-Won Park, Jin-Seok Choi and Jun-Shik Choi ${ }^{1 \dagger}$ \\ Department of Food and Drug \\ ${ }^{1}$ College of Pharmacy, Chosun University, Gwangiu, Republic of Korea \\ (Received August 29, $2011 \cdot$ Revised September 22, $2011 \cdot$ Accepted October 8, 2011)
}

\begin{abstract}
The aim of this study was to investigate the effects of kaempferol on the pharmacokinetics of nimodipine in rats. Nimodipine and kaempferol interact with cytochrome P450 (CYP) enzymes and P-glycoprotein (P-gp), and the increase in the use of health supplements may result in kaempferol being taken concomitantly with nimodipine as a combination therapy to treat orprevent cardiovascular disease. The effect of kaempferol on P-gp and CYP3A4 activity was evaluated and Pharmacokinetic parameters of nimodipine were determined in rats after an oral $(12 \mathrm{mg} / \mathrm{kg})$ and intravenous $(3 \mathrm{mg} / \mathrm{kg})$ administration of nimodipine to rats in the presence and absence of kaempferol $(0.5,2.5$, and $10 \mathrm{mg} / \mathrm{kg})$. Kaempferol inhibited CYP3A4 enzyme activity in a concentration-dependent manner with $50 \%$ inhibition concentration $\left(\mathrm{IC}_{50}\right)$ of $17.1 \mu \mathrm{M}$. In addition, kaempferol significantly enhanced the cellular accumulation of rhodamine-123 in MCF-7/ ADR cells overexpressing P-gp. Compared to the oral control group, the area under the plasma concentration-time curve $\left(\mathrm{AUC}_{0-\infty}\right)$ and the peak plasma concentration $\left(\mathrm{C}_{\max }\right)$ of nimodipine significantly increased, respectively. Consequently, the absolute bioavailability of nimodipine in the presence of kaempferol $(2.5$ and $10 \mathrm{mg} / \mathrm{kg}$ ) was $29.1-33.3 \%$, which was significantly enhanced compared to the oral control group (22.3\%). Moreover, the relative bioavailability of nimodipine was 1.30- to 1.49-fold greater than that of the control group. The pharmacokinetics of intravenous nimodipine was not affected by kaempferol in contrast to those of oral nimodipine. Kaempferol significantly enhanced the oral bioavailability of nimodipine, which might be mainly due to inhibition of the CYP3A4-mediated metabolism of nimodipine in the small intestine and /or in the liver and to inhibition of the P-gp efflux transporter in the small intestine by kaempferol. The increase in oral bioavailability of nimodipine in the presence of kaempferol should be taken into consideration of potential drug interactions between nimodipine and kaempferol.
\end{abstract}

Key words - Nimodipine, Kaempferol, Pharmacokinetics, Bioavailability, P-gp, CYP3A4, Rats

Nimodipine is a dihydropyridine calcium channel blocker that has been shown to selectively dilate cerebral arteries and increase cerebral blood flow in animals and humans (Kazda et al., 1982). Its major therapeutic indication is for the prevention and treatment of delayed ischemic neurological disorders that often occur in patients with subarachnoid hemorrhages (Epstein and Loutzenhister, 1990; Scholz, 1997). Nimodipine is rapidly absorbed after oral administration and is widely distributed throughout the body. Orally administered nimodipine is subject to an extensive first-pass hepatic metabolism from the portal circulation, resulting in a low systemic bioavailability (Maruhn et al., 1985; Suwelack et al., 1985). Usually only the parent compound is active and most of the metabolic steps involve reactions catalyzed by cytochrome P450 (CYP) enzymes. CYP enzymes have been shown to catalyze pyridine

${ }^{\dagger}$ Corresponding Author :

Tel : +82-62-230-6365, E-mail : jsachoi@chosun.ac.kr DOI : 10.4333/KPS.2011.41.5.301 formation, methyl hydroxylation, and various modes of sidechain oxidation (Ramsch et al., 1985; Scherling et al., 1991).

The reduced bioavailability of nimodipine after administering nimodipine orally might not only be due to the metabolizing enzyme CYP3A4, but also to the P-glycoprotein efflux transporter in the small intestine. Saeki et al. (1993) reported that nimodipine is a substrate for the efflux of P-glycoprotein and Wacher et al. (1998) reported that nimodipine is both a CYP3A4 and P-glycoprotein substrate. In the small intestine, P-glycoprotein is co-localized at the apical membrane of the cells with CYP3A4 (Gottesman and Pastan, 1993). P-glycoprotein and CYP3A4 may act synergistically to presystemic drug metabolism to make the substrate of P-glycoprotein circulate between the lumen and epithelial cells, leading to prolonged exposure to CYP3A4, resulting in a reduced absorption of the drug (Gan et al., 1996; Ito et al., 1999; Watkins, 1996).

Flavonoids are phytochemicals produced in high quantities by various plants (Dixon and Steel, 1999). These compounds exhibit a wide range of beneficial biological activities includ- 
ing antioxidative, radical scavenging, antiatherosclerotic, antitumor and antiviral effects (Nijveldt et al., 2001). Flavonoids also modulate the CYP3A subfamily and/or P-glycoprotein (Chieli et al., 1995; Di Pietro et al., 2002; Lee et al., 1994).

Kaempferol (3,4',5,7-tetrahydroxyflavone), a flavonoid, is most widely distributed in onion, carrot, and black tea; contents of kaempferol were 832,140 , and $118 \mathrm{mg} / \mathrm{kg}$ of dry weight, respectively (Miean et al., 2001). Kaempferol is also a CYP3A4 inhibitor (Pal et al., 2006). Kaempferol has been reported to be a substrate (Wang et al., 2004) and an inhibitor (Wang et al., 2005) of P-gp. But the effect of kaempferol on CYP3A4 and P-glycoprotein inhibition is partially ambiguous. Thus, we reevaluated CYP3A4 and P-glycoprotein activity using rhodamine-123 retention assay in P-glycoprotein overexpressed adriamycin-resistant human breast cancer cell line (MCF-7/ADR).

For example, kaempferol exhibited a remarkable inhibition of P-gp-mediated efflux of ritonavir, thus cellular uptake of ritonavir increased (Patel et al., 2004). Thus, it could be expected that kaempferol would change pharmacokinetics of nimodipine by inhibiting P-gp and CYP3A4 in rats.

Furthermore, since kaempferol has become readily available over-the-counter, it is possible that kaempferol products would be taken along with prescribed nimodipine for the therapy of cardiovascular disease. There are a few interactions between flavonoids and nimodipine (Choi and Burm, 2006). But there is not any report about the pharmacokinetic interaction between nimodipine and kaempferol in vivo.

Therefore, the aim of this study was to examine the effects of kaempferol on the CYP3A4, P-glycoprotein activity and pharmacokinetics of nimodipine after oral and intravenous administration with kaempferol in rats.

\section{Materials and Methods}

\section{Materials}

Nimodipine, nitrendipine (internal standard) and kaempferol were purchased from the Sigma Chemical Co. (St. Louis, MO, USA). Ethyl acetate and methanol were purchased from Merck Co. (Darmstadt, Germany). All other chemicals were reagent grade and were used without further purification. The apparatuses used included HPLC (Model LC-10A, Shimadzu Co., Kyoto, Japan), a syringe pump (Model341B, Sage Co., Kyoto, Japan), a vortex mixer (Scientific Industries, Seoul, Korea) and a centrifuge (Abbot Co., TM, USA).

\section{Animal experiments}

Male Sprague-Dawley rats (weighing 270-300 g) were pur- chased from the Dae Han Laboratory Animal Research Co. (Choongbuk, Korea), and were given access to a commercial rat chow diet (No. 322-7-1, Superfeed Co., Gangwon, Korea) and tap water. The animals were housed, two per cage, and maintained at $22 \pm 2{ }^{\circ} \mathrm{C}$ and $50-60 \%$ relative humidity, under a $12 \mathrm{~h}$ light-dark cycle. The experiments were initiated after acclimation under these conditions for at least 1 week. The Animal Care Committee of Chosun University (Gwangju, Korea) approved the design and conduction of this study. The rats were fasted for at least $24 \mathrm{~h}$ prior to the experiments and each animal was anaesthetized lightly with ether. The left femoral artery and vein were cannulated using polyethylene tubing (SP45, i.d. $0.58 \mathrm{~mm}$, o.d. $0.96 \mathrm{~mm}$; Natsume Seisakusho Co. LTD., Tokyo, Japan) for blood sampling and IV injection, respectively.

\section{Drug administration}

The rats were divided into four groups $(n=6)$; an oral control group $(12 \mathrm{mg} / \mathrm{kg}$ of nimodipine dissolved in distilled water, $3.0 \mathrm{~mL} / \mathrm{kg}$ ) with or without $0.5,2.5$ and $10 \mathrm{mg} / \mathrm{kg}$ of kaempferol (mixed in distilled water, $3.0 \mathrm{~mL} / \mathrm{kg}$ ), and an intravenous (IV) group (3 mg/kg of nimodipine, dissolved in $0.9 \%$ $\mathrm{NaCl}$ solution, $1.5 \mathrm{~mL} / \mathrm{kg}$ ). Oral nimodipine was administered intragastrically using a feeding tube, and kaempferol was administered in the same manner $30 \mathrm{~min}$ prior to the oral administration of nimodipine. Nimodipine for IV administration was injected through the femoral vein within $0.5 \mathrm{~min}$. A 0.4-aliquot of blood was collected into heparinized tubes from the femoral artery at 0 (to serve as control), 0.25, 0.5, 1, $2,3,4,8,12,24$ and $36 \mathrm{~h}$ after nimodipine administration. The blood samples were centrifuged at $16,800 \mathrm{~g}$ for $5 \mathrm{~min}$, and the plasma samples were stored at $-40^{\circ} \mathrm{C}$ until HPLC analysis.

\section{HPLC assay}

The plasma nimodipine concentration was determined by an HPLC assay using a modification of the method reported by Qian et al. (1992). Briefly, $50 \mu \mathrm{L}$ of nitrendipine ( $1 \mu \mathrm{g} / \mathrm{mL})$, as the internal standard, and $50 \mu \mathrm{L}$ of ethyl acetate were added to $0.2 \mathrm{~mL}$ of the plasma samples. The mixture was stirred for $10 \mathrm{~min}$ and centrifuged at 3,000 rpm for $10 \mathrm{~min}$. Next, $5 \mathrm{~mL}$ of the organic layer was transferred to a clean test tube and evaporated at $40^{\circ} \mathrm{C}$ under a stream of nitrogen. The residue was then dissolved in $300 \mu \mathrm{L}$ of $65 \%$ methanol, which was centrifuged at 3,000 rpm for $10 \mathrm{~min}$, and $50 \mu \mathrm{L}$ of the solution was injected into the HPLC system.

The HPLC system consisted of two solvent delivery pumps (Model LC-10AD, Shimadzu Co., Japan), a UV detector (Model SPD-10A), a system controller (Model SCL-10A), degasser 
(Model DGU-12A) and an auto injector (SIL-10AD). The UV detector was set at a wavelength of $310 \mathrm{~nm}$. The stationary phase used was a Hypersil ODS column $(5 \mu \mathrm{m}, 4.6 \times 150 \mathrm{~mm})$. The mobile phase consisted of methanol: water $(65: 35, \mathrm{v} / \mathrm{v})$. The mobile phase was filtered by passing through a $0.45 \mu \mathrm{m}$ pore size membrane filter. The retention times at a flow rate of $1.0 \mathrm{~mL} / \mathrm{min}$ were as follows: Internal standard, $7.6 \mathrm{~min}$; nimodipine, $9.1 \mathrm{~min}$. Linear regression analysis using a least-square fit was performed. The calibration curve was obtained from the standard samples at the following concentration: 10, 20, 50, 100,500 , and $1000 \mathrm{ng} / \mathrm{mL}$. The following regression equations were obtained: $\mathrm{y}=206.0 \mathrm{x}+18.1(\mathrm{r}=0.999)$. The limit of detection (LOD) of nimodipine in rat's plasma was $3.3 \mathrm{ng} / \mathrm{mL}$ $(\mathrm{LOQ}=10 \mathrm{ng} / \mathrm{mL})$. The coefficients of variation for nimodipine were below $12.5 \%$.

\section{CYP3A4 inhibition assay}

The assay of inhibition on human CYP3A4 enzyme activity was performed in a multiwell plate using CYP inhibition assay kit (GENTEST, Woburn, MA) as described previously (Crespi et al., 1997). Briefly, human CYP enzyme was obtained from baculovirus-infected insect cells. CYP substrate (7-Benzyloxy4-trifluoromethyl couamrin; BFC) was incubated with or without test compounds in the enzyme/substrate contained buffer with 1 pmol of P450 enzyme and an NADPH-generating system (1.3 mM NADP, $3.54 \mathrm{mM}$ glucose 6-phosphate, $0.4 \mathrm{U} / \mathrm{ml}$ glucose 6-phosphate dehydrogenase and $3.3 \mathrm{mM} \mathrm{MgCl}_{2}$ ) in a potassium phosphate buffer ( $\mathrm{pH}$ 7.4). Reactions were terminated by adding stop solution after $45 \mathrm{~min}$ incubation. Metabolite concentrations were measured by spectrofluorometer (Molecular Device, Sunnyvale, CA) at an excitation wavelength of $409 \mathrm{~nm}$ and an emission wavelength of $530 \mathrm{~nm}$. Positive control ( $1 \mu \mathrm{M}$ ketoconazole for CYP3A4) was run on the same plate and produced $99 \%$ inhibition. All experiments were done in duplicate, and the results were expressed as the percent of inhibition.

\section{Rhodamine-123 retention assay}

MCF-7/ADR cells were seeded in 24-well plates. At $80 \%$ confluence, the cells were incubated in fetal bovine serum (FBS)-free Dulbecco's modified eagle medium (DMEM) for $18 \mathrm{~h}$. The culture medium was changed to Hanks' balanced salt solution and the cells were incubated at $37^{\circ} \mathrm{C}$ for $30 \mathrm{~min}$. After incubation of the cells with $20 \mu \mathrm{M}$ rhodamine- 123 in the presence or absence of kaempferol $(50$ and $100 \mu \mathrm{M})$ and verapamil (positive control, $100 \mu \mathrm{M}$ ) for $90 \mathrm{~min}$, the medium was completely removed. The cells were then washed three times with ice-cold phosphate buffer ( $\mathrm{pH}$ 7.0) and lysed in EBC lysis buffer. Rhodamine-123 fluorescence in the cell lysates was measured using excitation and emission wavelengths of 480 and $540 \mathrm{~nm}$, respectively. Fluorescence values were normalized to the total protein content of each sample and are presented as the ratio to control.

\section{Pharmacokinetic analysis}

The plasma concentration data were analyzed using a noncompartmental method from WinNonlin software version 4.1 (Pharsight Co., Mountain View, CA, USA). The elimination rate constant $\left(\mathrm{K}_{\mathrm{el}}\right)$ was calculated by the log-linear regression of nimodipine concentration data during the elimination phase, and the terminal half-life $\left(\mathrm{t}_{1 / 2}\right)$ was calculated by $0.693 / \mathrm{K}_{\mathrm{el}}$. The peak concentration $\left(\mathrm{C}_{\max }\right)$ and time to reach the peak concentration $\left(T_{\max }\right)$ of nimodipine in the plasma were obtained by a visual inspection of the data from the concentration-time curve. The area under the plasma concentrationtime curve $\left(\mathrm{AUC}_{0-\mathrm{t}}\right)$ from time zero to the time of the last measured concentration $\left(\mathrm{C}_{\text {last }}\right)$ was calculated using the linear trapezoidal rule. The AUC zero to infinity $\left(\mathrm{AUC}_{0-\infty}\right)$ was obtained by adding $\mathrm{AUC}_{0-\mathrm{t}}$ and the extrapolated area was determined by $\mathrm{C}_{\text {last }} /$ $\mathrm{K}_{\mathrm{el}}$. The total body clearance for IV route $\left(\mathrm{CL}_{\mathrm{t}}\right)$ was calculated from $\mathrm{D} / \mathrm{AUC}$, where $\mathrm{D}$ is the dose of nimodipine. The absolute bioavailability (A.B.) of nimodipine was calculated by $\mathrm{AUC}_{\text {oral }} /$ $\mathrm{AUC}_{\mathrm{IV}} \times$ Dose $_{\mathrm{IV}} /$ Dose $_{\text {oral }} \times 100$, the relative bioavailability (R.B.) was calculated by $\left(\mathrm{AUC}_{\text {control }} / \mathrm{AUC}_{\text {with kaempferol }}\right) \times 100$.

\section{Statistical analysis}

All data were presented as means with standard deviation. The analysis of variance (ANOVA) with Scheffe's test was used to determine any significant differences between the control groups and co-administration or pretreatment groups. A P value $<0.05$ was considered significant.

\section{Results}

\section{Inhibition of CYP3A4}

The inhibitory effect of kaempferol on CYP3A4 activity was shown in Figure 1. Kaempferol inhibited CYP3A4 activity in a concentration-dependent manner. Kaempferol inhibited human CYP3A4 with $50 \%$ inhibition concentration $\left(\mathrm{IC}_{50}\right)$ values of $17.1 \mu \mathrm{M}$.

\section{Rhodamine-123 retention assay}

Accumulation of rhodamine-123, a P-glycoprotein substrate, raised in MCF-7/ADR cells overexpressing P-glycoprotein compared to that in MCF-7 cells lacking P-glycoprotein, as shown in Figure 2. The concurrent use of kaempferol enhanced 

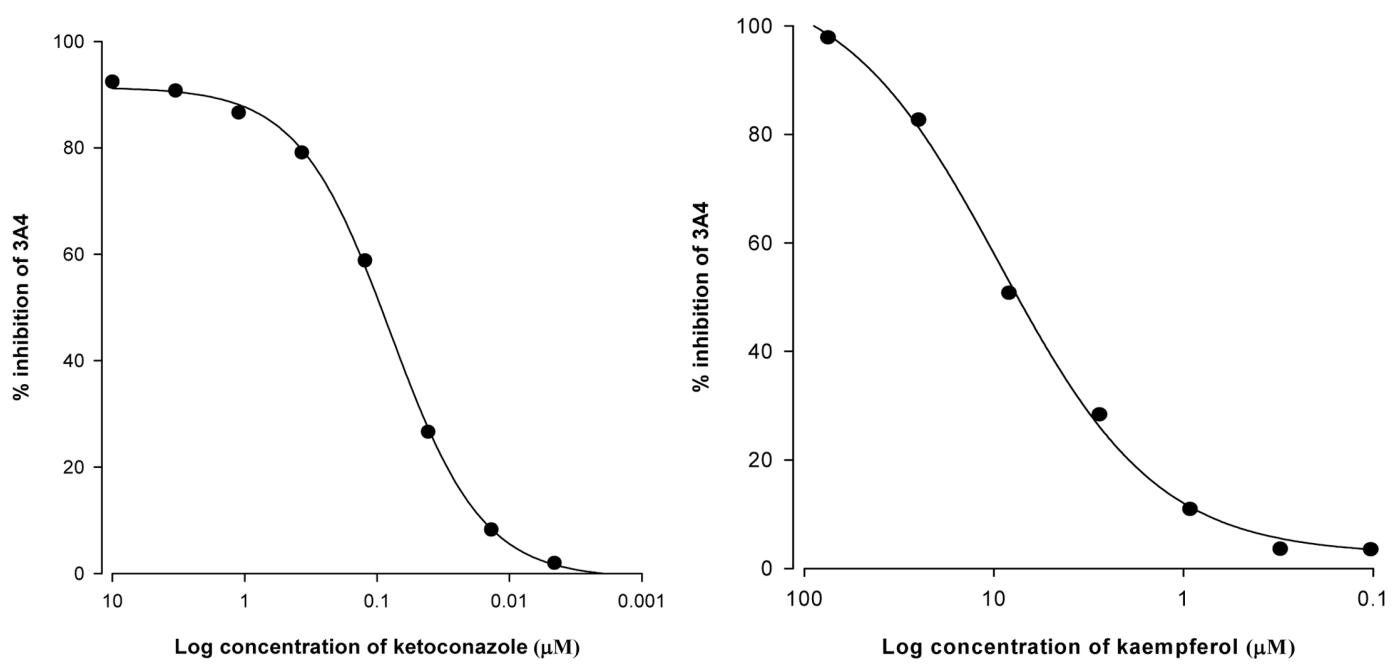

Figure 1. Inhibitory effect of ketoconazole and kaempferol on CYP3A4 activity. All experiments were done in duplicate, and the results were expressed as the percent of inhibition.

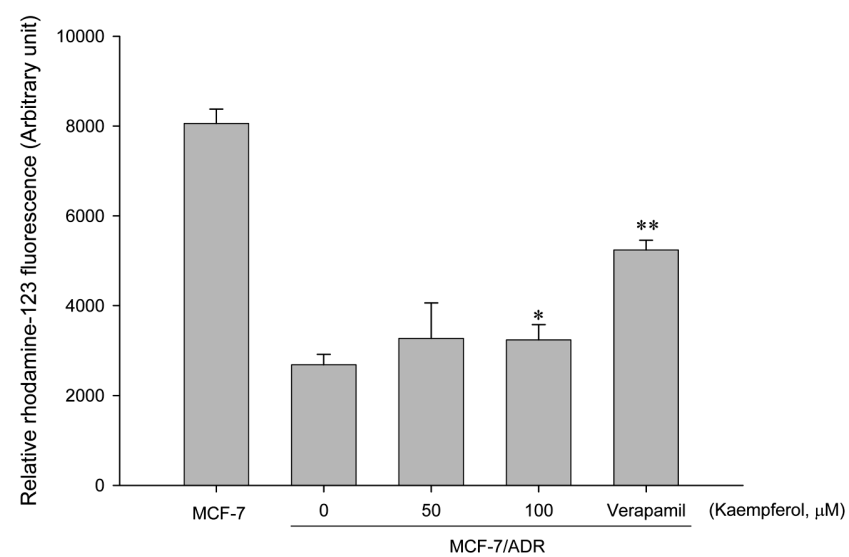

Figure 2. Rhodamine-123 retention. MCF-7/ADR cells were incubated in FBS-free DMEM for $18 \mathrm{~h}$. After incubation of the cells with $20 \mu \mathrm{M}$ rhodamine-123 in the presence or absence of kaempferol $(50$ and $100 \mu \mathrm{M})$ for $90 \mathrm{~min}$. Data represents mean \pm S.D. of 6 samples (significant versus control MCF-7 cells. ${ }^{*} \mathrm{P}<0.05$, ${ }^{* *} \mathrm{P}<0.01$ ). Verapamil $(100 \mu \mathrm{M}$ was used as a positive control.

the cellular uptake of rhodamine-123 in a concentration-dependent manner ranging from $50-100 \mu \mathrm{M}$. This result suggests that kaempferol significantly $(\mathrm{P}<0.05$ for $100 \mu \mathrm{M})$ inhibited $\mathrm{P}$ glycoprotein activity.

Effect of kaempferol on the pharmacokinetics of oral nimodipine

Mean arterial plasma concentration-time profiles of nimodipine following an oral administration of nimodipine (12 mg/ $\mathrm{kg})$ to rats in the presence or absence of kaempferol $(0.5,2.5$ and $10 \mathrm{mg} / \mathrm{kg}$ ) were shown in Figure 3; the corresponding pharmacokinetic parameters were shown in Table I. Kaempferol significantly altered the pharmacokinetic parameters of nimo-

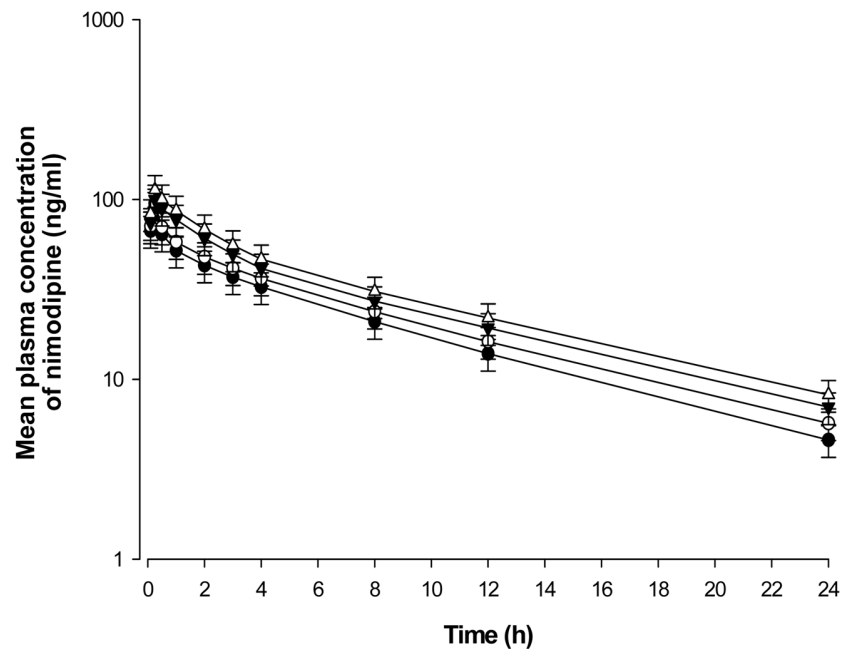

Figure 3. Mean plasma concentration-time profiles of nimodipine after the oral co-administration of nimodipine $(12 \mathrm{mg} / \mathrm{kg})$ with or without kaempferol to the rats. Bars represent the standard deviation $(\mathrm{n}=6)$. (O) $12 \mathrm{mg} / \mathrm{kg}$ of oral nimodipine, $(\bigcirc)$ with $0.5 \mathrm{mg} / \mathrm{kg}$ of kaempferol, $(\boldsymbol{\nabla})$ with $2.5 \mathrm{mg} / \mathrm{kg}$ of kaempferol, $(\triangle)$ with $10 \mathrm{mg} / \mathrm{kg}$ of kaempferol.

dipine. Compared to the control group (given oral nimodipine alone), kaempferol significantly $(\mathrm{P}<0.05$ for $2.5 \mathrm{mg} / \mathrm{kg}$, $\mathrm{P}<0.01$ for $10 \mathrm{mg} / \mathrm{kg}$ ) increased area under the plasma concentration-time curve $\left(\mathrm{AUC}_{0-\infty}\right)$ of nimodipine. Kaempferol also significantly ( $\mathrm{P}<0.05$ for $2.5 \mathrm{mg} / \mathrm{kg}, \mathrm{P}<0.01$ for $10 \mathrm{mg} / \mathrm{kg}$ ) increased the absolute bioavailability (A.B.) of nimodipine by $30.5-49.3 \%$ compared to the oral control group, and the relative bioavailability (R.B.) of nimodipine was increased by 1.30- to 1.49 -fold. The $C_{\max }$ and $t_{1 / 2}$ of nimodipine were increased but were not statistically significant in oral administration. 
Table I. Mean ( $\pm S . D$.) Pharmacokinetic Parameters of Nimodipine after Oral Administration of Nimodipine (12 mg/kg) to Rats with or without Kaempferol

\begin{tabular}{lcccc}
\hline \hline \multirow{2}{*}{ Parameter } & \multirow{2}{*}{ Control } & \multicolumn{3}{c}{ Nimodipine + kaempferol } \\
\cline { 3 - 5 } & & $0.5 \mathrm{mg} / \mathrm{kg}$ & $2.5 \mathrm{mg} / \mathrm{kg}$ & $10 \mathrm{mg} / \mathrm{kg}$ \\
\hline $\mathrm{AUC}_{0-\infty}(\mathrm{ng} \cdot \mathrm{h} / \mathrm{mL})$ & $509 \pm 110$ & $574 \pm 118$ & $664 \pm 127^{*}$ & $760 \pm 140^{* *}$ \\
$\mathrm{C}_{\max }(\mathrm{ng} / \mathrm{mL})$ & $91 \pm 14$ & $93 \pm 16$ & $97 \pm 16$ & $105 \pm 19$ \\
$\mathrm{~T}_{\max }(\mathrm{h})$ & 0.25 & 0.25 & 0.25 & 0.25 \\
$\mathrm{t}_{1 / 2}(\mathrm{~h})$ & $7.4 \pm 1.5$ & $7.7 \pm 1.8$ & $8.1 \pm 2.0$ & $8.4 \pm 2.3$ \\
A.B. (\%) & $22.3 \pm 4.6$ & $25.2 \pm 5.5$ & $29.1 \pm 5.9^{*}$ & $33.3 \pm 6.6^{* *}$ \\
R.B. (\%) & 100 & 112 & 130 & 149 \\
\hline
\end{tabular}

Mean \pm S.D., $(\mathrm{n}=6),{ }^{*} \mathrm{P}<0.05, * * \mathrm{P}<0.01$, significant difference compared to control group.

$\mathrm{AUC}_{0-\infty}$ : area under the plasma concentration-time curve from $0 \mathrm{~h}$ to infinity, $\mathrm{C}_{\max }$ : peak plasma concentration, $\mathrm{T}_{\max }$ : time to reach $\mathrm{C}_{\max }, \mathrm{t}_{1 / 2}$ : terminal half-life, A.B.: absolute bioavailability, R.B.: relative bioavailability.

Effect of kaempferol on the pharmacokinetics of IV nimodipine

Mean arterial plasma concentration-time profiles of nimodipine following an intravenous administration of nimodipine $(3 \mathrm{mg} / \mathrm{kg})$ to rats in the presence or absence of kaempferol $(0.5,2.5$ and $10 \mathrm{mg} / \mathrm{kg})$ were shown in Figure 4; the corresponding pharmacokinetic parameters were shown in Table II. The AUC of nimodipine was increased, but was not statistically significant compared to the the IV control group. $t_{1 / 2}$ of nimodipine was also prolonged, but this increase was not significant. The pharmacokinetics of intravenous nimodipine

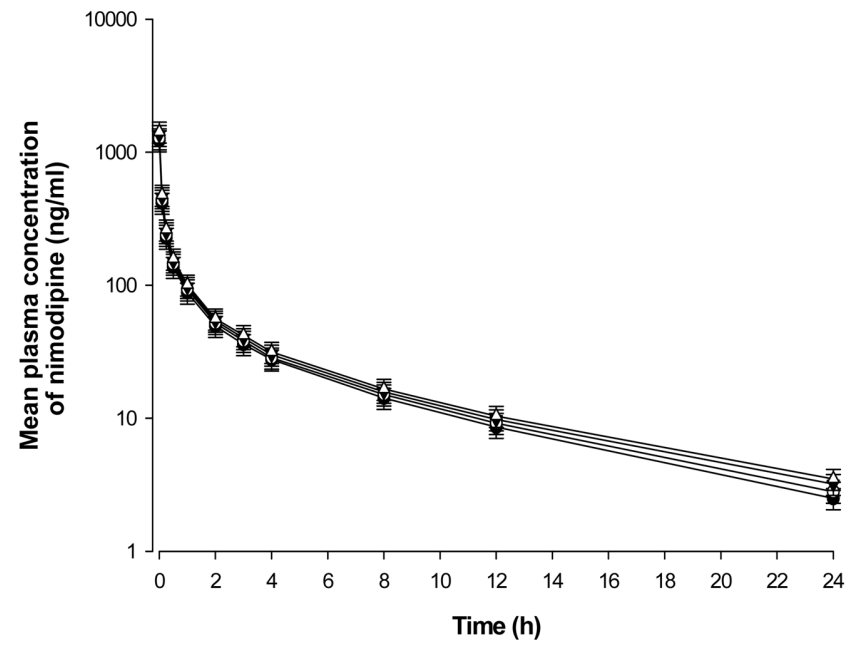

Figure 4. Mean plasma concentration-time profiles of nimodipine after IV administration of nimodipine $(3 \mathrm{mg} / \mathrm{kg}$ ) with or without kaempferol to the rats. Bars represent the standard deviation $(\mathrm{n}=6)$.

(O) $3 \mathrm{mg} / \mathrm{kg}$ of IV nimodipine, $(\bigcirc)$ with $0.5 \mathrm{mg} / \mathrm{kg}$ of kaempferol,

$(\boldsymbol{\nabla})$ with $2.5 \mathrm{mg} / \mathrm{kg}$ of kaempferol, $(\triangle)$ with $10 \mathrm{mg} / \mathrm{kg}$ of kaempferol.
Table II. Mean ( \pm S.D.) Pharmacokinetic Parameters of Nimodipine after Intravenous Administration of Nimodipine (3 $\mathrm{mg} / \mathrm{kg}$ ) to Rats with or without Kaempferol

\begin{tabular}{lcccc}
\hline \hline \multirow{2}{*}{ Parameter } & \multirow{2}{*}{ Control } & \multicolumn{3}{c}{ Nimodipine + kaempferol } \\
\cline { 3 - 5 } & & $0.5 \mathrm{mg} / \mathrm{kg}$ & $2.5 \mathrm{mg} / \mathrm{kg}$ & $10 \mathrm{mg} / \mathrm{kg}$ \\
\hline $\mathrm{AUC}_{0-\infty}(\mathrm{ng} \cdot \mathrm{h} / \mathrm{mL})$ & $570 \pm 116$ & $603 \pm 119$ & $615 \pm 121$ & $658 \pm 132$ \\
$\mathrm{CL}_{\mathrm{t}}(\mathrm{mL} / \mathrm{h} / \mathrm{kg})$ & $87 \pm 18$ & $84 \pm 17$ & $81 \pm 16$ & $76 \pm 15$ \\
$\mathrm{t}_{1 / 2}(\mathrm{~h})$ & $6.6 \pm 1.3$ & $6.8 \pm 1.4$ & $7.0 \pm 1.5$ & $7.1 \pm 1.5$ \\
R.B. (\%) & 100 & 105 & 108 & 115 \\
\hline
\end{tabular}

Mean \pm S.D., $(n=6)$.

$\mathrm{AUC}_{0-\infty}$ : area under the plasma concentration-time curve from $0 \mathrm{~h}$ to infinity, $\mathrm{CL}_{\mathrm{t}}$ : total body clearance, $\mathrm{t}_{1 / 2}$ : terminal half-life, R.B.: relative bioavailability.

was not affected by the concurrent use of kaempferol in contrast to those of oral nimodipine. Accordingly, the enhanced oral bioavailability in the presence of kaempferol, while there was no significant change in the pharmacokinetics of intravenous nimodipine, may be mainly due to inhibition of the CYP3A-mediated metabolism of nimodipine in the small intestine and /or in the liver, and to inhibition of the P-glycoprotein efflux transporter in the small intestine by kaempferol rather than renal elimination of nimodipine.

\section{Discussion}

With the great interest in herbal components as alternative medicines, much effort is currently being expended to identify natural compounds of plant origin that modulate P-glycoprotein and metabolic enzymes, however, there is far less information on the pharmacokinetic interactions between herbal components and medicines. More preclinical and clinical investigations on the herbal constituents-drug interaction should be performed to prevent potential adverse reactions in patients or to utilize those interactions for a therapeutic benefit. Therefore, the present study evaluated the effect of kaempferol, a naturally occurring flavonoid, on the pharmacokinetics of nimodipine in rats to examine a potential drug interaction between kaempferol and nimodipine via the dual inhibition of CYP3A4 and P-glycoprotein.

Nimodipine is metabolized by CYP3A4 in both the liver and small intestine (Ramsch et al., 1985; Scherling et al., 1991) and the absorption of nimodipine in the intestinal mucosa is inhibited by P-glycoprotein efflux pump (Saeki et al., 1993). In the small bowel, P-glycoprotein is co-localized at the apical membrane of the cells with CYP3A4 (Watkins, 1996). P-glycoprotein and CYP3A4 might act synergistically to limit oral absorption and the first-pass metabolism (Takino et al., 1987). 
Therefore, CYP3A4 and P-glycoprotein inhibitors have the potential to alter the pharmacokinetics of nimodipine. The inhibitory effect of kaempferol against CYP3A4 activity was confirmed by the use of recombinant CYP3A4 enzyme.

As shown in Figures 1 and 2, kaempferol exhibited an inhibitory effect against CYP3A4 and significantly $(\mathrm{P}<0.05)$ inhibited P-glycoprotein activity. These results are consistent with the previous report (Pal and Mitra, 2006; Wang et al., 2005). Therefore, the pharmacokinetic characteristics of nimodipine were evaluated in the absence and the presence of kaempferol in rats. As CYP3A9 expressed in rat is corresponding to the ortholog of CYP3A4 in human (Kelly et al., 1999) and human CYP2C9 and 3A4 and rat $\mathrm{CYP} 2 \mathrm{C} 11$ and 3A1 have 77 and $73 \%$, respectively, protein homology (Lewis, 1996). Rats were selected as an animal model in this study to evaluate the potential pharmacokinetic interactions mediated by CYP3A4, although there should be some difference in enzyme activity between rat and human (Cao et al., 2006).

It is possible that the concomitant administration of kaempferol might affect the bioavailability and pharmacokinetics of orally administered nimodipine. Since orally administered nimodipine is a substrate for CYP3A4-mediated metabolism and P-glycoprotein-mediated efflux in the intestine and in liver.

As shown in Tables I and II, kaempferol significantly increased area under the $\mathrm{AUC}_{0-\infty}$ of nimodipine given orally. The absolute bioavailability of nimodipine in the presence of kaempferol was significantly enhanced. This result is coincident with the previous study, that the presence of kaempferol significantly increased AUC of tamoxifen (Piao et al., 2008) and that kaempferol significantly increased AUC of etoposide (Li et al., 2009).

In contrast, kaempferol had no effect on any pharmacokinetic parameters of nimodipine given intravenously implying that coadministration of a kaempferol could inhibit CYP3A4mediated metabolism and P-glycoprotein-mediated efflux of nimodipine, resulting in reducing intestinal or hepatic firstpass metabolism. These results are consistent with a report by Choi et al. (2006) showing that morin significantly increased the $\mathrm{AUC}_{0-\infty}$ of nimodipine, a-glycoprotein and CYP3A4 substrate.

Kaempferol significantly enhanced the oral bioavailability of nimodipine, which might be primarily attributable to the promotion of intestinal absorption and reduction of first-pass metabolism of nimodipine in the intestinal and/or liver via inhibition of P-glycoprotein and CYP3A4 by kaempferol.

\section{Conclusion}

Kaempferol significantly enhanced the oral bioavailability of nimodipine, which might be mainly due to inhibition of the CYP3A4-mediated metabolism of nimodipine in the small intestine and /or in the liver, and to inhibition of the P-glycoprotein efflux pump in the small intestine by kaempferol rather than renal elimination of nimodipine. The increase in oral bioavailability of nimodipine in the presence of kaempferol should be taken into consideration of potential drug interactions between nimodipine and kaempferol.

\section{References}

Cao, X., Gibbs, S.T., Fang, L., Miller, H.A., Landowski, C.P., Shin, H.C., Lennernas, H., Zhong, Y., Amidon, G.L., Yu, L.X., Sun, D., 2006. Why is it challenging to predict intestinal drug absorption and oral bioavailability in human using rat model. Pharm. Res. 23, 1675-1686.

Chieli, E., Romiti, N., Cervelli, F., Tongiani, R., 1995. Effects of flavonols on P-glycoprotein activity in cultured rat hepatocytes. Life Sci. 57, 1741-1751.

Choi, J.S., Burm, J.P., 2006. Enhanced nimodipine bioavailability after oral administration of nimodipine with morin, a flavonoid, in rabbits. Arch. Pharm. Res. 29, 333-338.

Crespi, C.L., Miller, V.P., Penman, B.W., 1997. Microtiter plate assays for inhibition of human, drug-metabolizing cytochromes P450. Anal. Biochem. 248, 188-190.

Di Pietro, A., Conseil, G., Pérez-Victoria, J.M., Dayan, G., Baubichon-Cortay, H., Trompier, D., Steinfels, E., Jault, J.M., de Wet, H., Maitrejean, M., Comte, G., Boumendjel, A., Mariotte, A.M., Dumontet, C., McIntosh, D.B., Goffeau, A., Castanys, S., Gamarro, F., Barron, D., 2002. Modulation by flavonoids of cell multidrug resistance mediated by P-glycoprotein and related ABC transporters. Cell Mol. Life Sci. 59, 307-322.

Dixon, R.A., Steel, C.L., 1999. Flavonoids and isoflavonoids - a gold mine for metabolic engineering. Trend Plant Sci. 4, 394400.

Epstein, M., Loutzenhister, R.D., 1990. Effects of calcium antagonists on renal hemodynamics. Am. J. Kidney Dis. 16, 10-14.

Gan, L.L., Moseley, M.A., Khosla, B., Augustijns, P.F., Bradshaw, T.P., Hendren, R.W., Thakker, D.R., 1996. CYP3A-Like cytochrome P450-mediated metabolism and polarized efflux of cyclosporin A in Caco-2 cells: interaction between the two biochemical barriers to intestinal transport. Drug Metab. Dispos. 24, 344-349.

Gottesman, M.M., Pastan, I., 1993. Biochemistry of multidrug resistance mediated by the multidrug transporter. Annu. Rev. Biochem. 62, 385-427.

Ito, K., Kusuhara, H., Sugiyama, Y., 1999. Effects of intestinal CYP3A4 and P-glycoprotein on oral drug absorption theoretical approach. Pharm. Res. 16, 225-231. 
Kazda, S., Garthoff, B., Krause, H.P., Schlossmann, K., 1982. Cerebrovascular effects of the calcium antagonistic dihydropyridine derivative nimodipine in animal experiments. Arzneimittelforschung 32, 331-338.

Kelly, P.A., Wang, H., Napoli, K.L., Kahan, B.D., Strobel, H.W., 1999. Metabolism of cyclosporine by cytochromes P450 3A9 and 3A4. Eur. J. Drug Metab. Pharmacokinet. 24, 321-328.

Lee, H., Wang, H.W., Su, H.Y., Hao, N.J., 1994. The structureactivity relationships of flavonoids as inhibitors of cytochrome P-450 enzymes in rat liver microsomes and the mutagenicity of 2-amino-3-methyl-imidazo[4, 5-f]quinoline. Mutagenesis 9, 101-106.

Lewis, D.F.V., 1996. Cytochrome P450. Substrate specificity and metabolism. In: Cytochromes P450. Structure, Function, and Mechanism. Taylor \& Francis: Bristol. 122-123.

Li, C., Li, X., Choi, J.S., 2009. Enhanced bioavailability of etoposide after oral or intravenous administration with kaempferol in rats. Arch.Pharm. Res. 32, 133-138.

Maruhn, D., Siefert, H.M., Weber, H., Ramsch, K., Suwelack, D., 1985. Pharmacokinetics of nimodipine. communication: absorption, concentration in plasma and excretion after single administration of nimodipine in rat, dog and monkey. Arzneimittelforschung 5, 1781-1786.

Miean, K.H., Mohamed, S., 2001. Flavonoid (myricetin, quercetin, kaempferol, luteolin, and apigenin) content of edible tropical plants. J. Agric. Food Chem. 49, 3106-3112.

Nijveldt, R.J., van Nood, E., van Hoorn, D.E., Boelens, P.G., van Norren, K., van Leeuwen, P.A., 2001. Flavonoids: a review of probable mechanisms of action and potential applications. Am. J. Clin. Nutr. 74, 418-425.

Pal, D., Mitra, A.K., 2006. MDR- and CYP3A4-mediated drugherbal interactions. Life Sci. 78, 2131-2145.

Patel, J., Buddha, B., Dey, S., Pal, D., Mitra, A.K., 2004. In vitro interaction of the HIV protease inhibitor ritonavir with herbal constituents: changes in P-gp and CYP3A4 activity. Am. J. Ther. 11, 262-277.

Piao, Y., Shin, S.C., Choi, J.S., 2008. Effects of oral kaempferol on the pharmacokinetics of tamoxifen and one of its metabolites, 4-hydroxytamoxifen, after oral administration of tamoxifen to rats. Biopharm. Drug Dispos. 29, 245-249.

Qian, M., Gallo, J.M., 1992. High-perfomance liquid chromatographic determinination of the calcium channel blocker nimodipine in monkey plasma. J. Chromatogr. 578, 316-320.

Ramsch, K.D., Ahr, G., Tettenborn, D., Auer, L.M., 1985. Overview on pharmacokinetics of nimodipine in healthy volunteer and in patients with subarachnoid hemorrhage. Neurochirurgia 28, 74-78.

Saeki, T., Ueda, K., Tanigawara, Y., Hori, R., Komano, T., 1993. Pglycoprotein-mediated transcellular transport of MDR-reversing agents. FEBS Lett. 324, 99-102.

Scherling, D., Buhner, K., Krause, H.P., Karl, W., Wunsche, C., 1991. Biotransformation of nimodipine in rat, dog and monkey. Arzneimittelforschung 41, 392-398.

Scholz, H., 1997. Pharmacological aspects of calcium channel blockers. Cardiovasc. Drugs Ther. 10, 869-872.

Suwelack, D., Weber, H., Maruhn, D., 1985. Pharmacokinetics of nimodipine, communication: absorption, concentration in plasma and excretion after single administration of nimodipine in rat, dog and monkey. Arzneimittelforschung 35, 1787-1794.

Takino, Y., Miyahara, T., Arichi, E., Arichi, S., Hayashi, T., Karikura, M., 1987. Determination of some flavonoids in Scutellariae radix by high-performance liquid chromatography. Chem. Pharm. Bull. 35, 3494-3497.

Wacher, V.J., Silverman, J.A., Zhang, Y., Benet, L.Z., 1998. Role of P-glycoprotein and cytochrome P450 3A in limiting oral absorption of peptides and peptidomimetics. J Pharm Sci, 87, 1322-1330.

Wang, Y., Cao, J., Zeng, S., 2005. Involvement of P-glycoprotein in regulating cellular levels of Ginkgo flavonols: quercetin, kaempferol, and isorhamnetin. J. Pharm. Pharmacol. 57, 751758.

Wang, Y., Cao, J., Zeng, S., Inramonti, G., Donati, A., Chieli, E., 2004. Effects of grapefruit juice on the multidrug transporter P-glycoprotein in the human proximal tubular cell line HK-2. Life Sci. 76, 293-302.

Watkins, P.B., 1996. The barrier function of CYP3A4 and P-glycoprotein in the small bowel. Adv. Pharm. Drug Deliv. Rev. 27, 161-170. 